\title{
Simulation of Accelerated Ageing of UV-Radiation for Photodegradable Geotextiles/Geomembranes
}

\author{
Dr. V. G. Bhartu \\ 764-E, Umrigar Building, Tilak Road, Dadar, Mumbai 400014, India
}

\begin{abstract}
Geosynthetics used as geotextiles/geomembranes lose their mechanical properties when exposed to outdoor solar radiation. The UV-component present in the solar radiation is main cause for such degradation of mechanical properties. The life of geosynthetics has to be predicted before the intended purpose by exposing the material under artificial UV-radiation in the laboratory. Simulation of UV-radiation has been set up for accelerated ageing condition of Mumbai climate.
\end{abstract}

Key words: UV-radiation, solar radiation, geotextiles, geosynthetics.

\section{Introduction}

It is well established that geosynthetics when exposed to solar radiation lose their tensile strength and other mechanical properties. UV-portion present in solar radiation is main cause of degradation. The direct exposure under sunlight involves the synergistic effects of UV-degradation and elevated temperature. The intensity of light and the exposure period affect the rate of degradation. Life of geosynthetics has to be predicted before use of material in field considering the degradation of mechanical properties especially the degradation due to UV-radiation.

Eight test specimens of geotextile (PET/PP) and eight test specimens of geomembrane (PVC/HDPE) were exposed to outdoor solar radiation at Mumbai where the daily average incidental solar radiation is 5 $\mathrm{Kw} . \mathrm{h} / \mathrm{m}^{2} /$ day. Simulation of accelerated ageing condition was performed under artificial UV-radiation in laboratory. The rate of accelerated ageing was 1 hour of exposure under UV-lamp equal to 3 hours of outdoor exposure.

\section{Literature Review}

Coleman and Weicksel [1] suggested the incidental energy from sunlight is divided into three regions

Corresponding author: Vivek Ganesh Bhartu, Ph.D., consulting engineer, research field: geo-technical engineering. shown in Fig. 1; the infrared (about $760 \mathrm{~nm}$ ) visible light (760 nm to $400 \mathrm{~nm}$ ) and UV-region (below 400 $\mathrm{nm})$. The UV range may be further subdivided into three categories; UV-A (400 to $315 \mathrm{~nm}$ ) which cause some damage to polymers UV-B (315 to $280 \mathrm{~nm}$ ) which causes most severe polymer damage and UV-C (280 to $100 \mathrm{~nm}$ ) which would be extremely damaging to polymers but is found only in outer space.

G. R. Koerner [2] suggested that for considering the accelerated simulation of direct solar radiation, a worse case situation, which is the solar maximum condition. This condition consists of global, noon sunlight on the summer solestic at normal incidence. This response spectrum is shown as the upper curve in Fig. 1. It is suggested that the UV-B range is the target spectrum for laboratory devices to simulate the naturally occurring phenomenon.

Schneider and Groh [3] suggested that the energy incidence on a sample during exposure can be taken as parameter from which predictions can be made.

\section{Simulation of Accelerated Weathering Conditions}

The accelerated ageing conditions were simulated to determine the degradation of Geotextiles/Geomembranes due to UV-radiation in laboratory for various exposure conditions used in 


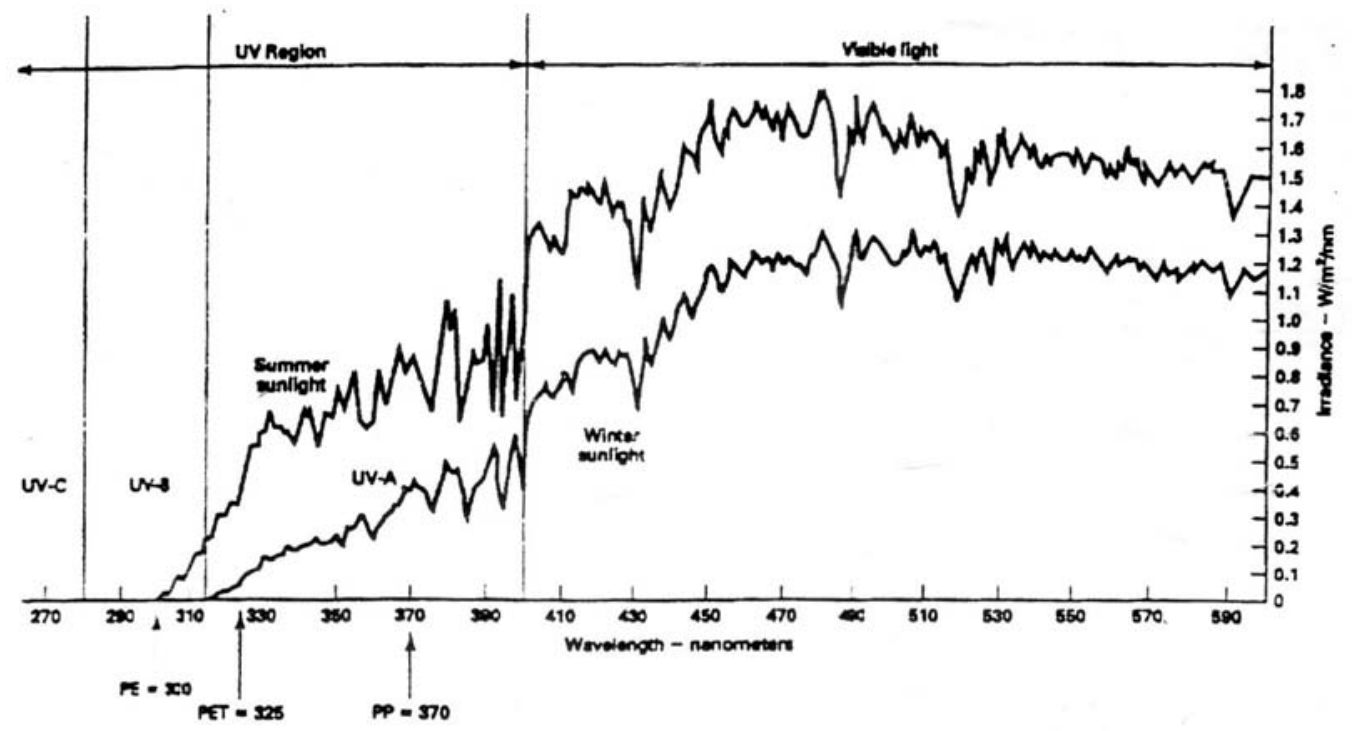

Fig. 1 Wavelength spectrum of solar radiation (Coleman and Weicksel 1959).

Table 1 Average daily total radiation in $\mathrm{MJ} / \mathrm{m}^{2}$.

\begin{tabular}{lllllllllll}
\hline & 1995 & 1996 & 1997 & 1998 & 1999 & 2000 & 2001 & 2002 & 2003 & 2004 \\
\hline January & 15.57 & 15.93 & 14.72 & 15.92 & 17.8 & 17.98 & 17.17 & 16.15 & 15.49 & 17.61 \\
February & 19.08 & 18.57 & 18.79 & 20.49 & 18.7 & 19.94 & 20.71 & 18.28 & 19.82 & 19.96 \\
March & 21.57 & 20.19 & 20.42 & 24.03 & 28.34 & 23.24 & 23.71 & 21.51 & 22.8 & 21.84 \\
April & 22.91 & 23.31 & 23.06 & 24.57 & 23.44 & 24.49 & 24.57 & 23.87 & 24.44 & 24.94 \\
May & 22.53 & 23.97 & 23.95 & 24.91 & 23.07 & 22.84 & 25.02 & 24.21 & 23.73 & 0 \\
June & 20.98 & 19.29 & 16.18 & 19.06 & 16.89 & 18.18 & 16.16 & 15.37 & 15.2 & 19.39 \\
July & 10.85 & 11.71 & 12.73 & 13.65 & 14.46 & 13.48 & 14.13 & 16.14 & 14.3 & 14.37 \\
August & 17.45 & 12.7 & 16.35 & 15.02 & 16.43 & 14.87 & 14.32 & 11.46 & 14.48 & 14.02 \\
September & 15.28 & 14.51 & 16.37 & 13.79 & 15.9 & 18.78 & 16.05 & 18.4 & 15.49 & 17 \\
October & 17.85 & 15.89 & 20.02 & 17.41 & 18.5 & 17.99 & 15.06 & 16.4 & 18.9 & 20.35 \\
November & 16.27 & 16.31 & 16.6 & 16.77 & 17.25 & 16.31 & 16.17 & 16.31 & 16.68 & 16.84 \\
December & 15.04 & 13.89 & 15.68 & 15.87 & 15.61 & 15.4 & 15.23 & 13.78 & 15.37 & 14.16 \\
\hline
\end{tabular}

engineering applications.

\section{Meteorological Data}

Meteorological data have been studied for Mumbai City for the last 10 years. The daily solar radiation (in $\mathrm{MJ} / \mathrm{M}^{2}$ ) and the corresponding daily bright sunshine hours have been obtained for the last 10 years (i.e. from 1995 to 2004) for Mumbai station and shown in Tables 1 and 2. The daily Solar Radiation has been averaged for each month of the year from 1995 to 2004 (Tables 1 and 2).

It has been observed from these data that the minimum daily Solar Radiation for Mumbai station is $10.85 \mathrm{MJ} / \mathrm{m}^{2}$ (July 1995) and the maximum is 28.34
$\mathrm{MJ} / \mathrm{m}^{2}$ (March 1999). It has also been observed from the Meteorological data available for Mumbai station that the bright Sunshine hours for last 10 years are 8 hours (average). The average daily Solar radiation for the last 10 years is considered to be $18 \mathrm{MJ} / \mathrm{m}^{2} /$ day equivalent to $5,000 \mathrm{~W} . \mathrm{h} . / \mathrm{m}^{2} /$ day or the intensity is 625 $\mathrm{W} / \mathrm{m}^{2}$.

It has been reported by the previous researchers that the UV-component in solar radiation in the Northern hemisphere of earth is $6.8 \%$ and in the southern hemisphere is $9.9 \%$. Considering the location of India on the earth, the UV-component in the total Solar Radiation is considered as $6.8 \%$. Hence the $\mathrm{UV}$-component in average daily Solar radiation is, 
Table 2 Average daily total sunshine hours.

\begin{tabular}{lllllllllll}
\hline & 1995 & 1996 & 1997 & 1998 & 1999 & 2000 & 2001 & 2002 & 2003 & 2004 \\
\hline January & 9.58 & 9.21 & 9.4 & 8.73 & 9.67 & 9.2 & 8.32 & 8.67 & 8.3 & 8.83 \\
February & 9.92 & 8.97 & 10.31 & 9.28 & 9.95 & 9.14 & 9.45 & 9.19 & 9.58 & 9.62 \\
March & 9.02 & 9.1 & 9.41 & 9.81 & 9.52 & 9.84 & 9.7 & 9 & 9.57 & 8.75 \\
April & 8.4 & 0 & 9.3 & 9.88 & 9.18 & 9.42 & 9.41 & 10.19 & 9.75 & 9.46 \\
May & 6.46 & 0 & 10.52 & 9.16 & 7.95 & 8.11 & 8.82 & 9.18 & 8.8 & 8.09 \\
June & 7.16 & 0 & 5.23 & 4.96 & 5.07 & 4.42 & 5.22 & 3.88 & 3.89 & 4.58 \\
July & 0 & 0 & 3.56 & 1.53 & 2.35 & 2.75 & 1.49 & 3.82 & 2.08 & 2.66 \\
August & 0 & 0 & 4.13 & 2.4 & 3.36 & 2.77 & 3.08 & 1.84 & 2.71 & 4.91 \\
September & 4.27 & 5.95 & 6.44 & 3.27 & 4.6 & 6.42 & 5.61 & 6.34 & 4.6 & 5.5 \\
October & 8.38 & 6.22 & 9.32 & 6.56 & 8.23 & 7.86 & 8.15 & 7.73 & 8.55 & 8.51 \\
November & 8.36 & 9.54 & 8.7 & 8.46 & 9.46 & 8.59 & 8.84 & 8.75 & 8.64 & 9.05 \\
December & 8.18 & 8.08 & 8.78 & 8.64 & 9.33 & 8.55 & 8.27 & 8.71 & 8.09 & 8.41 \\
\hline
\end{tabular}

$$
5000 \times 0.068=340 \text { w.h. } / \mathrm{m}^{2} / \text { day }
$$

In order to verify the UV-component in daily solar radiation, UV-light meter (Model UV-340) and solar light meter were used. The solar radiation at various time in a day was measured by Lux-meter (Solar meter) in $\mathrm{w} / \mathrm{m}^{2}$ and the corresponding UV-component was measured by UV-meter in $\mathrm{mw} / \mathrm{m}^{2}$. The study confirmed that the UV-component in solar radiation in Mumbai station is $6.8 \%$.

\subsection{Intensity of UV—Radiation \& Luminance Flux}

Intensity of Light is measured by "LUX" in metric unit and the light flow (Luminance flux) is measured by "LUMEN".

By definition,

$$
\begin{aligned}
& 1 \mathrm{Lux}=1 \mathrm{Lumen} / \mathrm{m}^{2} \text { and } \\
& 1 \mathrm{Lux}=0.0161028 \mathrm{w} / \mathrm{m}^{2}
\end{aligned}
$$

The intensity of Solar radiation was measured by Lux meter at various time for seven days (from $21 / 10 / 2006$ to $28 / 10 / 2006$ ). It has been observed that the values of Lux from 8:00 A.M. to 6:00 P.M. (10 hours) with the intervals of 2 hours are $35,000,81,500$, 98,500, 97,000, 68,000, and 1,500 Lux. The average intensity of Solar radiation has been found as 42,000 lux. Converting the same into $\mathrm{w} / \mathrm{m}^{2}$ unit,

$42,000 \times 0.0161028=676 \mathrm{w} / \mathrm{m}^{2}$ which is very close to the average value $\left(625 \mathrm{w} / \mathrm{m}^{2}\right)$ of Solar radiation obtained from meteorological data.

From Eq. (1) above,
UV component in average daily Solar radiation is 340 w.h. $/ \mathrm{m}^{2} /$ day. Hence intensity of $\mathrm{UV}=\frac{340}{8}$ w.h $/ \mathrm{m}^{2}$.

(Since 1 day has 8 hours of sunshine $)=42.5 \mathrm{w} / \mathrm{m}^{2}$.

Converting $42.5 \mathrm{w} / \mathrm{m}^{2}$ into Lux (by Eq. (2)) = 2,639.29 Lux say 2,640 Lux.

Intensity of UV-component in daily Solar Radiation is 2,640 Lux.

\subsection{Accelerated Ageing Condition}

Accelerated ageing conditions were simulated in laboratory for the UV-radiation intensity of $2640 \mathrm{Lux}$.

The acceleration rate has been selected as 1 hour radiation in laboratory equal to half day radiation of the outdoor exposure where one day has 8 hours bright sunshine hours.

Hence the required intensity of UV-light in laboratory is,

$$
2,640 \times 4=10,560 \text { Lux }
$$

\subsection{Size of Experimental Set up in Laboratory}

Following samples were exposed under artificial UV-lamp in laboratory.

4 samples of Polypropylene of size $45 \mathrm{~cm} \times 45 \mathrm{~cm}$ (each).

4 samples of Polyester of size $45 \mathrm{~cm} \times 45 \mathrm{~cm}$ (each).

4 samples of PVC of size $45 \mathrm{~cm} \times 25 \mathrm{~cm}$ (each).

4 samples of HDPE of size $45 \mathrm{~cm} \times 25 \mathrm{~cm}$ (each).

Thus, the required exposure area was found to be 
$180 \mathrm{~cm} \times 140 \mathrm{~cm}$.

\subsection{Selection of UV-Lamps}

Special UV lamps for emitting UV-radiation between wavelength of $280 \mathrm{~nm}$ to $400 \mathrm{~nm}$ were selected. This lamp has width of $120 \mathrm{~cm}$ and diameter of $3.25 \mathrm{~cm}$. The lamp is in the form of tube having 2.9 $\mathrm{w} / \mathrm{m}^{2} \mathrm{UV}$-radiation at a distance of 1 meter from lamp. This lamp requires $40 \mathrm{w}$. power and $9.3 \mathrm{w}$. UV-output as stated by the manufacturer. Hence, the Lux value of the lamp at a distance of $1 \mathrm{~m}$ of lighting has been determined as,

$$
\frac{2.9}{0.0161028}=180.1 \mathrm{Lux}
$$

The output of UV-radiation of $2.9 \mathrm{w} / \mathrm{m}^{2}$ at a distance of $1 \mathrm{~m}$ from the tube has been verified by UV meter which is 180 Lux.

It has been reported by earlier researchers that the Lux value of light changes with the distance from the source of light and the same is inverse square of the distance from the source of the original Lux value i.e. from 1 meter distance from source.

Hence, the distance between the lamp and the exposed material samples was kept at $0.15 \mathrm{~m}$ in order to increase Lux value.

Thus, the output of the light source was found to be,

$$
180.1 \times \frac{1}{(0.15)^{2}}=8,004.44 \text { lux }
$$

Whereas the required intensity of UV-lamp in laboratory was 10,560 Lux as derived earlier in Eq. (3). Hence, the rate of accelerated ageing has been revised as,

$$
\frac{128.84 \mathrm{w} / \mathrm{m}^{2}}{42.50 \mathrm{w} / \mathrm{m}}=3.03 \mathrm{hrs}
$$

1 hour exposure in laboratory $=3.0$ hour or 0.375 day of outdoor exposure.

\subsection{Checking the Intensity of Lamp for Peak Intensity of Solar Radiation}

From the meteorological data available for last 10 years, it has been observed that the peak solar radiation during 12:00 Noon to 1:00 P.M. is $4 \mathrm{MJ} / \mathrm{m}^{2}$.
Converting the same into $\mathrm{w} / \mathrm{m}^{2}$ the same is,

$$
\frac{4 \mathrm{X} 1000000}{3600}=1,111 \mathrm{w} . \mathrm{h} . / \mathrm{m}^{2}
$$

The peak intensity of solar radiation is $1,111 \mathrm{w} / \mathrm{m}^{2}$.

However, this intensity has been obtained by Meteorological Studies observed by taking various readings between 12:00 Noon to 1:00 P.M. at the 5 minutes intervals and the averaging the same as 4 $\mathrm{MJ} / \mathrm{m}^{2}$.

It is, therefore, decided to observe the intensity of solar radiation at various time during 12:00 Noon to 1:00 P.M. by Lux meter.

It has been observed that the peak intensity of solar radiation in a day is $98,500 \mathrm{Lux}$. equivalent to $1,586.13$ $\mathrm{w} / \mathrm{m}^{2}$.

Considering $1,586.13 \mathrm{w} / \mathrm{m}^{2}$ is the peak intensity of solar radiation, the UV-Component in the peak intensity is,

$1,586.13 \times 0.068=107.86 \mathrm{w} / \mathrm{m}^{2}$ equivalent to 6,698 Lux.

The intensity of UV-light in the laboratory has been selected as 8,004 Lux which more than the peak intensity of UV-component in Solar radiation. Hence, the effect of the peak intensity on Geotextiles/Geomembrances like weakening of molecular bonds shall be covered by the proposed intensity of UV-lamp in laboratory.

\subsection{Requirement of Number of UV-Lamps and Their Spacing}

The most important aspect in simulation of accelerated ageing condition in laboratory is selection of number of lamps and the spacing between the lamps. It is necessary to emit the light rays uniformly on the exposed samples to avoid the complicated situations. If the lamps are very close to each other, the intersecting portion will be more affected than the non-intersecting portion as shown in Fig. 2 and, if the lamps are very far from each other, some portion of the material even though exposed to radiation shall remain unaffected or less affected as shown in Fig. 3. 
In order to avoid the above situation, following approach has been chosen.

It is verified that the light rays reach to horizontal surface by making the angle $58^{0} 30^{\prime}$ without changing the intensity of light (Beyond the angle $58^{0} 30^{\prime}$, the intensity of light reduces.) as shown in Fig. 4.

Intensity of light on portion $\mathrm{AB}$ shall be more than

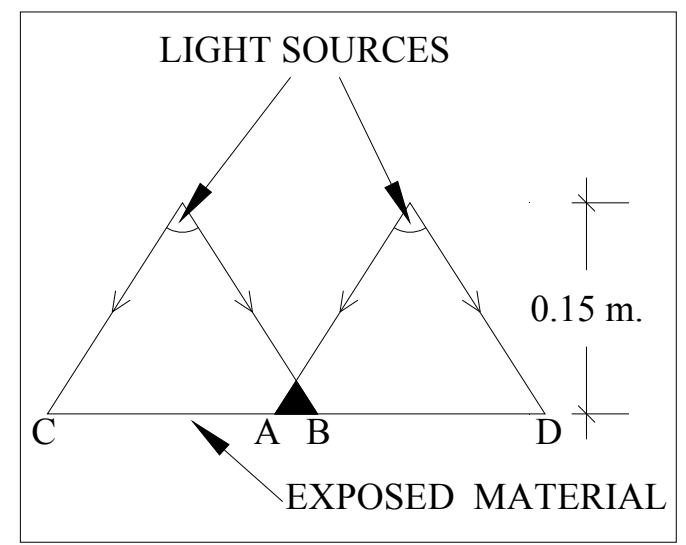

Portion $\mathrm{AB}$ shall be more affected than $\mathrm{AC} \& \mathrm{BD}$

Fig. 2 Overlapping of UV-radiation.

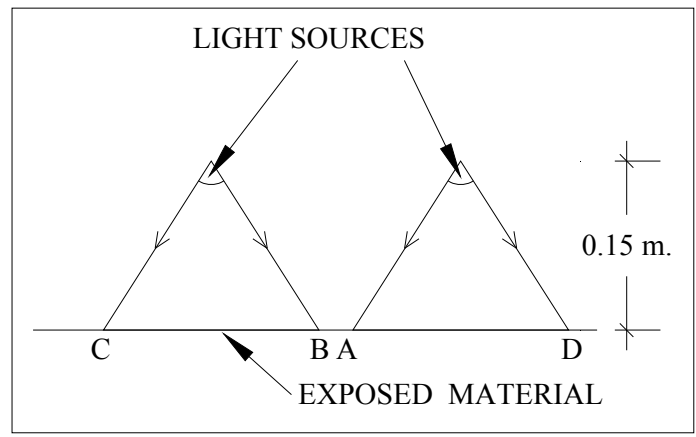

Portion $\mathrm{AB}$ shall remain unaffected

Fig. 3 Partial effect of UV-radiation.

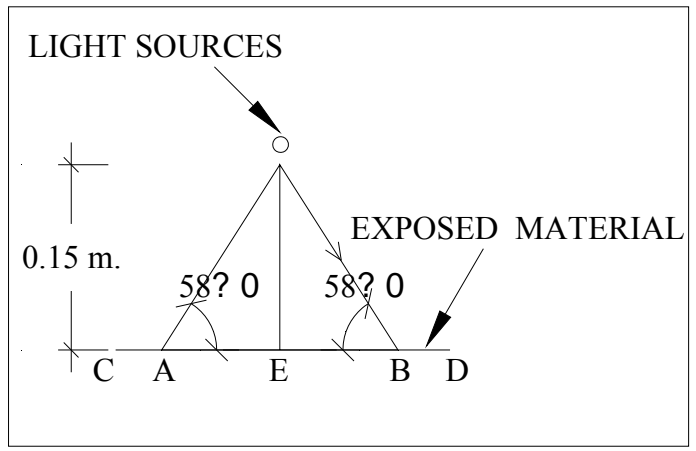

Fig. 4 Uniform distribution of UV-radiation. on portion $\mathrm{AC}$ and portion $\mathrm{BD}$ (this can be also verified by lux meter).

The distance $\mathrm{OE}$ shall be $15 \mathrm{~cm}$ (as required in Eq. (4)).

$$
\text { Distance } \mathrm{AE}=\frac{15}{{\operatorname{Tan} 58^{0} 30}^{\prime}}=9.19 \mathrm{~cm}=\mathrm{BE}
$$

Hence the distance $A B=18.38 \mathrm{~cm}$ which may be the distance between the lamps to avoid overlapping of radiation or unaffected portion of sample by radiation.

No. of lamps required $=\frac{180}{18.38} \approx 9+1=10$ No. of lamps.

\subsection{Experimental Set up with UV-Lamps in Laboratory}

The required exposure size of materials is $180 \mathrm{~cm} \times$ $140 \mathrm{~cm}$. The setup has been shown in Fig. 5 .

In this type of arrangement of UV-lamps, the intensity of light shall be uniform on the plane of exposed material. However, the actual UV intensity on the exposed material has been measured by UV meter at various horizontal points and the same has been found as 7,920 Lux.

Actual Lux value $=7,920$ Lux

Theoretical Lux value = 8,004 Lux (As per 4 above).

Rate of accelerated ageing shall be,

1 hour in laboratory $=\frac{7920}{2640}=3$ hours of outdoor exposure

$$
=\frac{3 h r}{8 h r}=0.375 \text { day. }
$$

Duration of exposure of specimen in laboratory:

The Geotextile/Geomembrane specimens were exposed under the UV-lamp in the laboratory for a duration of $150 \mathrm{hr}, 300 \mathrm{hr}$ and $450 \mathrm{hr}$ for various conditions i.e. free exposure, submerged in water, in contact with soil and combination of water and soil. After the specified duration, the specimens were removed and the physical/mechanical/microstructural properties have been tested. 


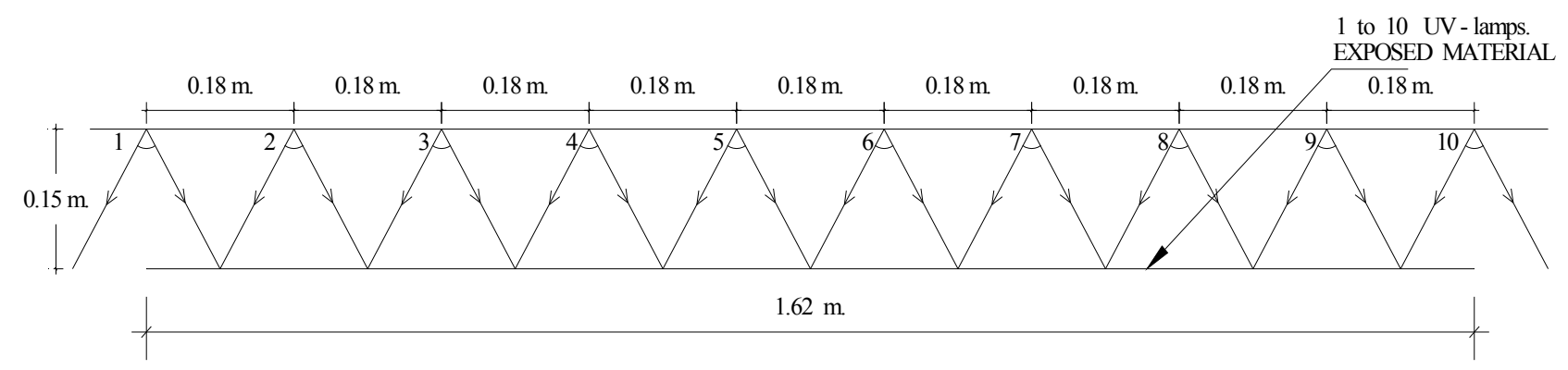

Fig. 5 Experimental set up of simulation of UV-radiation in laboratory.

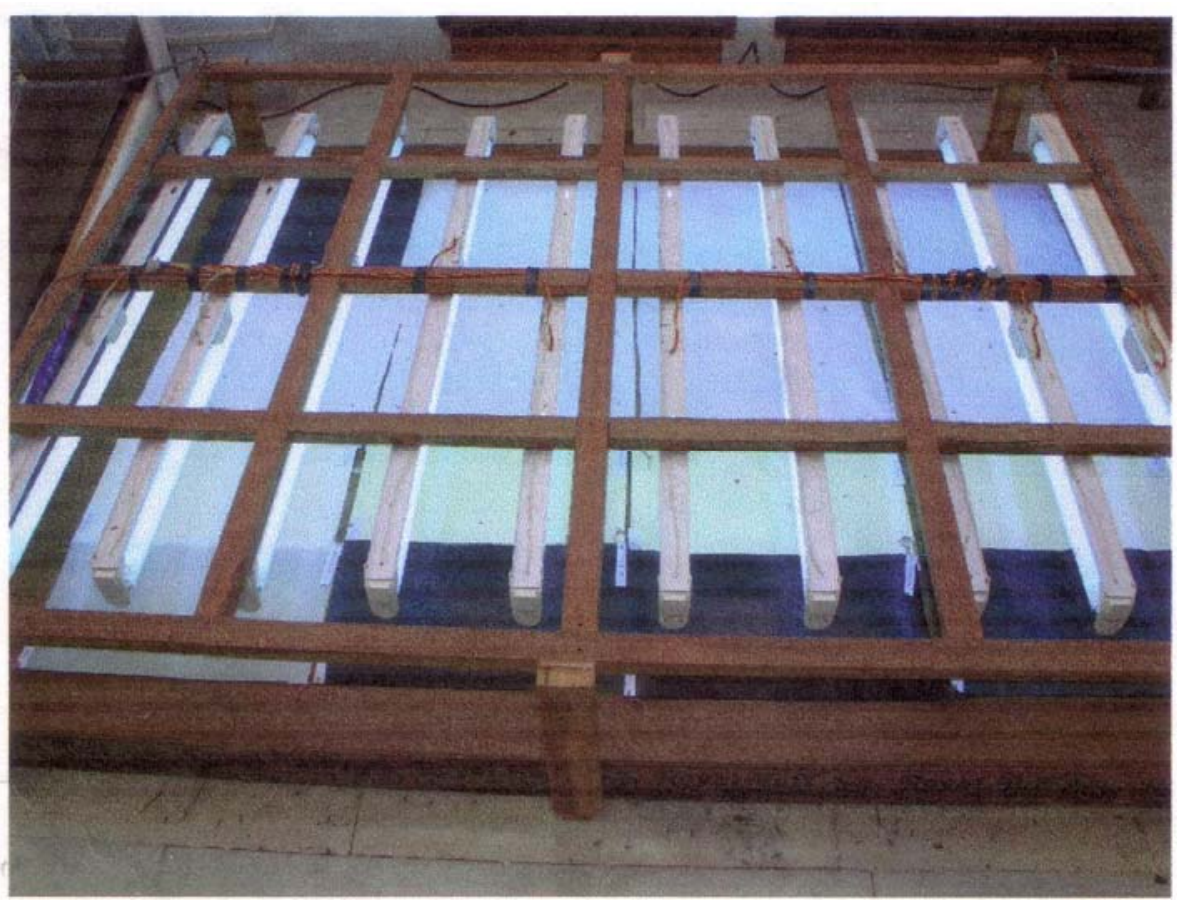

Fig. 6 Test specimens exposed under artificial UV—lamp.

\section{Conclusions}

Geotextile/geomembrane test specimens are tested with the help of the simulated UV-radiation set-up made by the present theory and the results for degradation of mechanical properties are determined. From the results, it has been observed that Geotextile/geomembrane test specimens exposed under artificial UV-radiation in the laboratory shows the degradation of mechanical properties; tensile strength, flexural strength etc. The amount of degradation increases with the increase in the exposure period. The amount of degradation further depends upon the conditions under which test specimens are exposed to UV-radiation. The amount of degradation is maximum when the test specimens exposed are in contact with soil and water and the same reduces when the test specimens come in contact with only soil. The amount of degradation reduces when test specimens are submerged in water and exposed to UV-radiation. Simulation study shows that life of geotextile/geomembrane test specimens can be predicted before intended use with the help of co-relation studies between accelerated ageing condition in laboratory and outdoor solar radiation exposure. The details of co-relation equation have been presented in International Geotechnical Conference 2010 in Mumbai. 


\section{References}

[1] Coleman, R. A., and Weicksel, J. A. 1959. Ultraviolet Absorbers for Plastics 198 (Aug.), 117-21.

[2] Koerner, G. R. 1998. "Photo-Initiated Degradation of
Geo-textile." Journal of Geo-Technical and Geo-Environmental Engineering 124 (12): 1159-66.

[3] Schneider and Groh. 1987. "An Analysis of the Durability Problems of Geotextiles." In Proc. of Geosynthetics 87 Conf., 434-41. 